\title{
Kinetic and Isotherm Studies on Adsorption of Nickel (II) Ions by Brassera Oleracea as a Bioadsorbent
}

\author{
R. Muthuselvi ${ }^{1}$, R. Vashantha* ${ }^{2}$ \\ ${ }^{1}$ Assistant Professor of Chemistry, Sri Meenakshi Govt. Arts College for Women, Madurai, Tamil Nadu, India \\ ${ }^{2}$ Assistant Professor of Chemistry, Anna Adarsh College for Women, Chennai, India
}

\begin{abstract}
An increase in population initiating rapid industrialization was found to consequently increase the effluents into the aquatic ecosystem. brassera oleracea - Cabbage, a vegetable wastes were used to produce bioadsorbent through environment friendly process. It were cut, washed, dried, grounded into powder and used for nickel(II) removal. Nickel(II) adsorption onto raw cabbage(RC) was depended upon the controlling parameters such as $\mathrm{pH}$, contact time, initial concentration, adsorbent dosage, particle size and temperature. pH 5 was found to be suitable for nickel(II) removal. Equilibrium, thermodynamic and kinetic data were well fitted $\left(R^{2}=\right.$ 0.991). Various thermodynamic parameters such as $\Delta G^{o}, \Delta H^{o}$ and $\Delta S^{o}$ have also been evaluated and it has been found that the adsorption process was spontaneous, endothermic and randomness in nature. The experimental data were analyzed using the Freundlich, Langmuir and Temkin adsorption isotherm equations. The equilibrium data were found to fit well in the Langmuir isotherm, which confirmed the monolayer coverage of $\mathrm{Ni}(\mathrm{II})$ ions onto $\mathrm{RC}$. The monolayer adsorption capacity was $13.63 \mathrm{mg} / \mathrm{g}$. The $\mathrm{R}_{\mathrm{L}}$ and ' $n$ ' values has proved the favorability of nickel(II) adsorption onto raw cabbage. The uptake of metal ions normally follows pseudo-first order kinetics and the adsorption capacity increase at elevated temperatures. The results indicate that the RC can be used to effectively adsorb nickel(II) ions from wastewater.
\end{abstract}

Keywords: adsorbent, metal ion, adsorption, isotherms, kinetics, thermodynamic parameter

\section{Introduction}

The increase in usage of heavy metals in industrial activities has caused the existence of them in waste water. For example lead, cadmium and nickel which the waste water of industries such as electroplating, plastic and paint manufacturing, mining, metallurgical process, petrochemical process, batteries, paper and pulp contains them ${ }^{1}$. In the discharge of metal ions in industrial effluent using biosorption process has been an area of extensive research because of the presence and accumulation of toxic carcinogenic effect on living species ${ }^{2}$. A conventional method for removing metals from industrial effluents includes chemical precipitation, coagulation, solvent extraction, electrolysis and adsorption. Most of these methods suffer with high capital and regeneration costs of the material ${ }^{3}$. Therefore, there is currently a need for new and cost effective methods for the removal of toxic substances from wastewaters. Biosorption is an effective and versatile method and can be easily adopted in low cost to remove heavy metals from large amount of industrial wastewaters. Agricultural materials contain proteins, polysaccharides and lignin which are associated with functional groups responsible for metal ion adsorption ${ }^{4}$. In recent years, agricultural by-products have been widely studied from metal removal from water. These include peat, wood, bark, husk, dust, peel and leaves. The purpose of this present study was to assess the ability of brassera oleracea (Cabbage) to adsorb $\mathrm{Ni}(\mathrm{II})$ ions from aqueous solutions. The experiments were done in batch system and nickel adsorption was investigated with respect to $\mathrm{pH}$, contact time, initial metal ion concentration, adsorbent dose, particle size and temperature. The main aim of this research was to determine the potentiality and adsorption capacity of raw cabbage(RC) as a bioadsorbent.

\section{Materials and Methods}

\subsection{Materials}

Nickel solution was prepared by diluting 1000ppm of nickel nitrate (Merck) stock solution with double distilled water. Different concentrations of metal solutions (5 to $25 \mathrm{mg} / \mathrm{L}$ ) were prepared by dissolving required amount of stock solution.

Adsorbent: Cabbage was collected locally and washed under a tape water to remove any particulate and again washed with double distilled water. This bioadsorbent was cut into small pieces, oven dried, crushed and sieved without any further treatment. The adsorbent was called it as RC (Raw Cabbage) for further studies.

Characterization of adsorbents: The physical characteristics of the adsorbent samples were determined by known methods ${ }^{5}$. The $\mathrm{pH}$ values of the adsorbent slurry was determined by mixing $2 \mathrm{~g}$ of adsorbent in $100 \mathrm{~mL}$ of double distilled water and $\mathrm{pH}$ was recorded at every $3 \mathrm{~h}$ interval for a period of $24 \mathrm{~h}$. The results showed that the $\mathrm{pH}$ of the slurry was nearly constant. The Electrical conductivity of the adsorbent sample was measured by mixing $2 \mathrm{~g}$ of adsorbent in $100 \mathrm{~mL}$ of deionised water and conductivity was measured at every $2 \mathrm{~h}$ interval for a total period of $12 \mathrm{~h}$. Density of the adsorbents was found by specific gravity estimation method ${ }^{6}$. The adsorbent was packed in a dry 25 $\mathrm{mL}$ bottle and weighed. The mean value was obtained by repeating the experiment for five times to calculate the 


\section{International Journal of Science and Research (IJSR) \\ ISSN (Online): 2319-7064}

Index Copernicus Value (2013): 6.14 | Impact Factor (2015): 6.391.1

density of the adsorbent. Weight loss of the adsorbent was determined by standard methods. The samples were sieved using the British Standard Sieves BSS 52, BSS 30 and BSS 25 to obtain particles of various sizes. The actual size of the particles was determined using Occular Micrometer.

Surface area determination The surface area of the adsorbent was measured by p-nitrophenol method ${ }^{7}$. pNitrophenol was recrystallized twice from water and $0.695 \mathrm{~g}$ was weighed and $50 \mathrm{mM}$ stock solution was prepared. Various concentrations, 3, 4, 5, 6, 7, 8 and $9 \mathrm{mM}$ of pnitrophenol were prepared from the stock solutions. In a typical experiment 1 of adsorbent sample with $0.36-0.48 \mathrm{~mm}$ of particle size was mixed with $3 \mathrm{mM}$ concentration of $\mathrm{p}$ nitrophenol in a $100 \mathrm{~mL}$ flask and the mixture was mechanically shaken at $301 \mathrm{~K}$ until adsorption equilibrium was reached. Similar procedure was repeated for all other concentrations of p-nitrophenol and adsorption was followed. After an hour of agitation time the flasks were set aside for 15 minutes to allow the adsorbent for complete settlement. The supernatant solution was decanted and absorbance was measured at 400nm wavelength in the UVVisible spectrophotometer. The experiments were repeated for adsorbents with particles of varying sizes. Surface area was determined using the relation. S.A $=x_{m} N$ A $\left(\mathrm{m}^{2} / g\right)$ where, $\mathrm{X}_{\mathrm{m}}{ }^{\text {e }}$ is the monolayer capacity in moles per gram, ${ }_{\mathrm{N}} \mathrm{N}^{\mathrm{ee}}$ the Avagadro number, , $A^{\text {ee }}$ the area of surface occupied by each solute molecule in sq.cm.

\subsection{Adsorption Studies}

Batch adsorption experiments were carried out by agitating $0.4 \mathrm{~g}$ of the adsorbent with $200 \mathrm{ml}$ of nickel(II) ion solutions of desired concentrations and $\mathrm{pH} 5$ at room temperature using an mechanical shaker at $150 \mathrm{rpm}$. The effect of $\mathrm{pH}$ was studied by adjusting $\mathrm{pH}$ of the solution using $1 \mathrm{~N} \mathrm{HCl}$ or $1 \mathrm{~N} \mathrm{NaOH}$ solution the $\mathrm{pH}$ was measured using a $\mathrm{pH}$ meter. The effect of initial metal ion concentrations was carried out by shaking 5, 9,13,17,21 and 25mg/L with $400 \mathrm{mg}$ of adsorbent with $200 \mathrm{ml}$ of metal solution and $\mathrm{pH} 5$ at room temperature. All the investigations were carried out in duplicate to avoid any discrepancy in experimental results and metal solution controls were kept throughout the experiment to maintain quality control. The percentage of metal adsorption by the adsorbents was using the equation(1).

$$
\text { Adsorption (\%) }=\mathrm{C}_{0}-\mathrm{C}_{\mathrm{e}} / \mathrm{C}_{0} \times 100
$$

where $\mathrm{C}_{0}$ and $\mathrm{C}_{\mathrm{e}}$ are the initial and equilibrium concentration of metal ion $(\mathrm{mg} / \mathrm{L})$ in the solution. Adsorption capacity was calculated by using the mass balance equation for the adsorbent using equation(2)

$$
q=\left(C_{0}-C_{e}\right) X v / m
$$

where, $\mathrm{q}^{\mathrm{ec}}$ is the amount adsorbed(mg/g), ,m $\mathrm{m}^{\mathrm{ec}}$ is the weight of sorbent, , $\mathrm{V}^{\text {ee }}$ is the volume of metal solution. The amount of metal ion sorbed at equilibrium, , qe is calculated using equation 2 .

\section{Results and Discussion}

Table 1: Physical properties of Raw Cabbage

\begin{tabular}{|l|l|}
\hline \multicolumn{1}{|c|}{ Parameters } & Raw Cabbage(RC) \\
\hline $\mathrm{pH}$ & 5.2 \\
$\mathrm{EC}(\mu \mathrm{S} / \mathrm{cm})$ & 0.367 \\
Density $(\mathrm{g} / \mathrm{ml})$ & 0.439 \\
Particle size $(\mathrm{mm})$ & $0.38-0.46$ \\
Surface area $\left(\mathrm{m}^{2} / \mathrm{g}\right)$ & 109.9 \\
\hline
\end{tabular}

\section{Adsorbent characterization}

The Scanning Electron Microscope (JSM-5610 model) machine was used to determine the structure of the adsorbent material. The morphological difference of the surface of the RC and metal ion loaded-RC are shown in Figure 1. SEM analysis revealed that there were significant changes on the surface texture and the porosity of the adsorbent has holes and small openings found on the surface indicate that these increase the contact areas which facilitate pore diffusion during adsorption. A foam like net anchored on the surface of the adsorbent corresponding to the adsorbed heavy metal ion on the surface ${ }^{8}$.

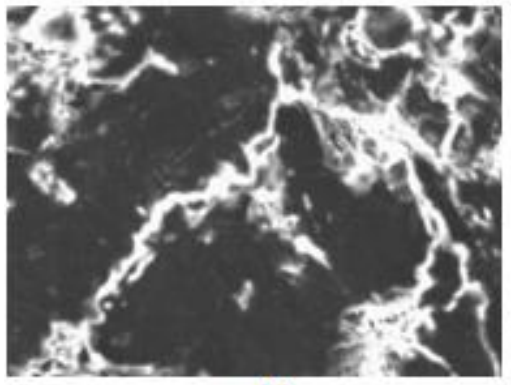

(a)

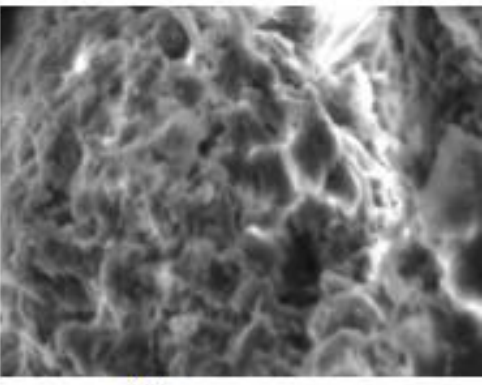

(b)

Figure 1: SEM images of (a) raw cabbage and (b) metal ion loaded raw cabbage

\section{Effect of pH}

The removal of metal ions from aqueous solution by adsorption was depended on the $\mathrm{pH}$ of the solution since it affected adsorbent surface charge, degree of ionization of the functional groups and metal ion speciation ${ }^{9}$. At lower $\mathrm{pH}$ value, the $\mathrm{H}^{+}$ions compete with metal cation for the exchange sites in the system thereby partially releasing the later. The heavy metal cations are completely released under circumstances of extreme acidic conditions. To find a suitable $\mathrm{pH}$ for the effective adsorption of $\mathrm{Ni}$ (II) ions, experiments were performed over a $\mathrm{pH}$ range of 3.0 to 9.0 . The variation of amount of metal ion adsorbed with initial $\mathrm{pH}$ is given Figure $\mathbf{2}$ for an initial nickel(II) ion concentration of $5 \mathrm{mg} / \mathrm{L}$ at $301 \mathrm{~K}$. Maximum nickel(II) adsorption was obtained at $\mathrm{pH}$ 5. This optimum $\mathrm{pH}$ obtained of 5.0 was used in all subsequent adsorption 


\section{International Journal of Science and Research (IJSR) \\ ISSN (Online): 2319-7064}

Index Copernicus Value (2013): 6.14 | Impact Factor (2015): 6.391.1

studies. It is observed from the figure that the initial $\mathrm{pH}$ of a solution played a major role in nickel adsorption. Under low $\mathrm{pH}$ conditions the adsorption of nickel(II) ions is not significant since the metal binding sites on the RC surface were closely associated with $\mathrm{H}_{3} \mathrm{O}^{+}$which restricted the approach of the positive nickel(II) ions due to repulsive forces ${ }^{10}$. However the adsorption capacity increase as $\mathrm{pH}$ increased since more metal binding sites were exposed with negative charges which attracted the positive $\mathrm{Ni}(\mathrm{II})$ ions into the surface of the adsorbent ${ }^{11}$.

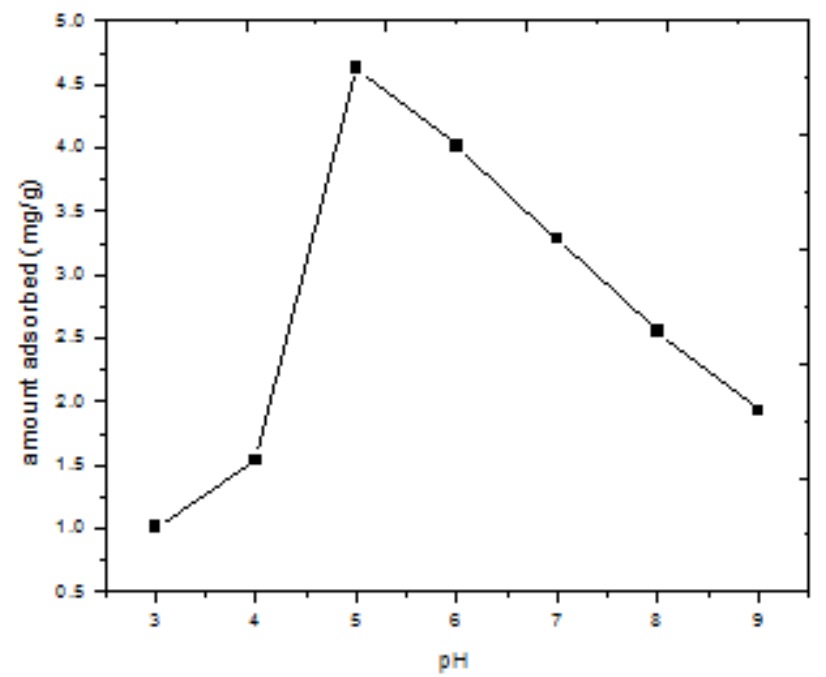

Figure 2: Effect of $\mathrm{pH}$ on the equilibrium nickel(II) ion sorption capacity of RC. Condition: initial metal concentration $=5 \mathrm{mg} / \mathrm{L}$, dosage $400 \mathrm{mg}$, particle size 0.38 $0.46 \mathrm{~mm}$ and room temperature

\section{Effect of contact time and initial concentration}

The contact time is one of the factors for the development of surface charges at the solid solution interface. At a fixed $\mathrm{pH}$, initial metal ion concentration and temperature, the result on the effect of varying the sorption time is presented in Figure 3. The adsorption rate was seen to increase rapidly at the initial stage and optimum adsorption was attained within 20 minutes. However, the maximum adsorption was obtained in 60 minutes. The fast initial uptake capacity is due to the availability of abundant active sites for sorption which became saturated with time ${ }^{12}$.

The initial concentration of adsorbate also plays an important role as a given mass of the adsorbent can adsorb only a fixed amount of the solute. The effect of initial nickel(II) ion concentration on adsorption by RC is presented in Figure 4. The removal of the Ni(II) ions by RC increased from 1.54 to $5.75 \mathrm{mg} / \mathrm{g}$ by increasing the concentration of the metal ion from 5 to $25 \mathrm{mg} / \mathrm{L}$ at temperature $301 \mathrm{~K}$ and $\mathrm{pH} 5$. The uptake capacity of RC for this metal ion increased with increase in initial concentration of nickel(II) ions. This is due to the presence of more metal ions in solution available for sorption. This increase in concentration increased the driving force overcoming resistances to mass transfer between the adsorbent and adsorbate species which led to the increase in adsorption observed $^{13}$. The time variation curves for adsorption are simple, smooth and continuous, indicating the formation of monolayer coverage on the surface of adsorbent ${ }^{14}$.

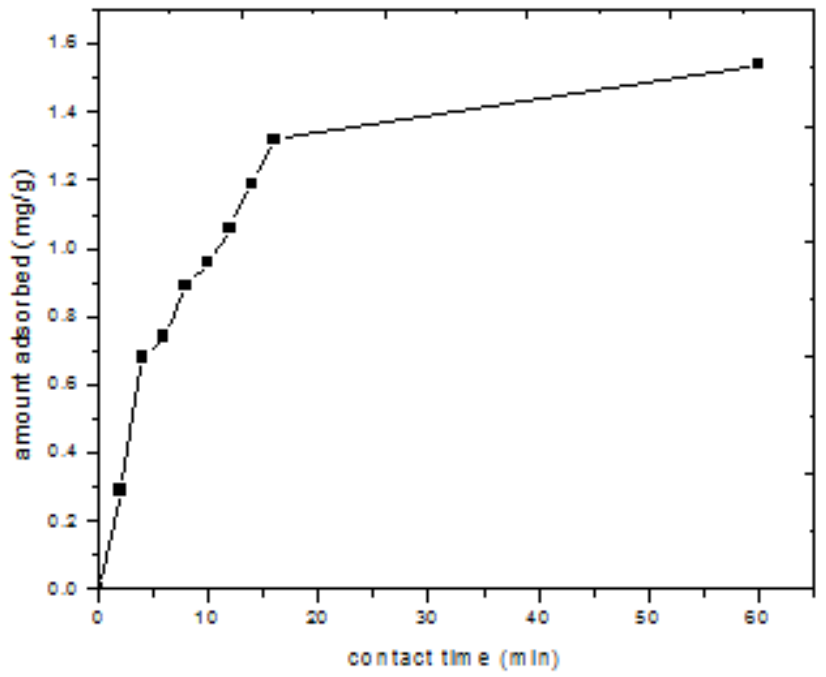

Figure 3: Effect of contact time on the adsorption of nickel(II) ions. Condition; $\mathrm{pH}=5.0$, Concentration of metal ion: $5 \mathrm{mg} / \mathrm{L}$, dosage $400 \mathrm{mg}$, particle size $0.38-0.46 \mathrm{~mm}$ and room temperature

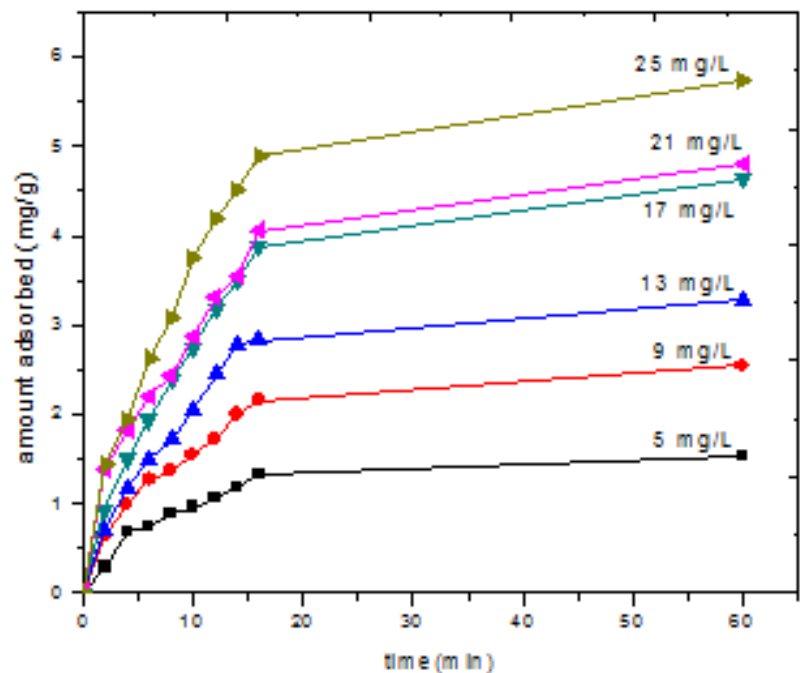

Figure 4: Effect of initial concentration of nickel (II) ion removal by RC. Conditions: $\mathrm{pH} 5$, dosage $400 \mathrm{mg}$, particle size $0.38-0.46 \mathrm{~mm}$ and room temperature

\section{Effect of adsorbent dosage}

The effect of variation of adsorbent dosage amount on the removal of metal ions by RC is shown in Figure 5. The percent removal of nickel was found to increase with an increase in the mass of adsorbent. Highest nickel removals were 77.3 to $80.8 \%$ for the initial nickel concentration of 5 $\mathrm{mg} / \mathrm{L}$ at the adsorbent doses were 400 and $800 \mathrm{mg} / 200 \mathrm{ml}$ under the optimized conditions. This may be attributed to overlapping or aggregation of adsorbent surface area available to ion and an increase in diffusion path length ${ }^{15}$. Also, due to lack of active binding site, the lower removals were obtained at low adsorbent does ${ }^{16}$. 
International Journal of Science and Research (IJSR)

ISSN (Online): 2319-7064

Index Copernicus Value (2013): 6.14 | Impact Factor (2015): 6.391.1

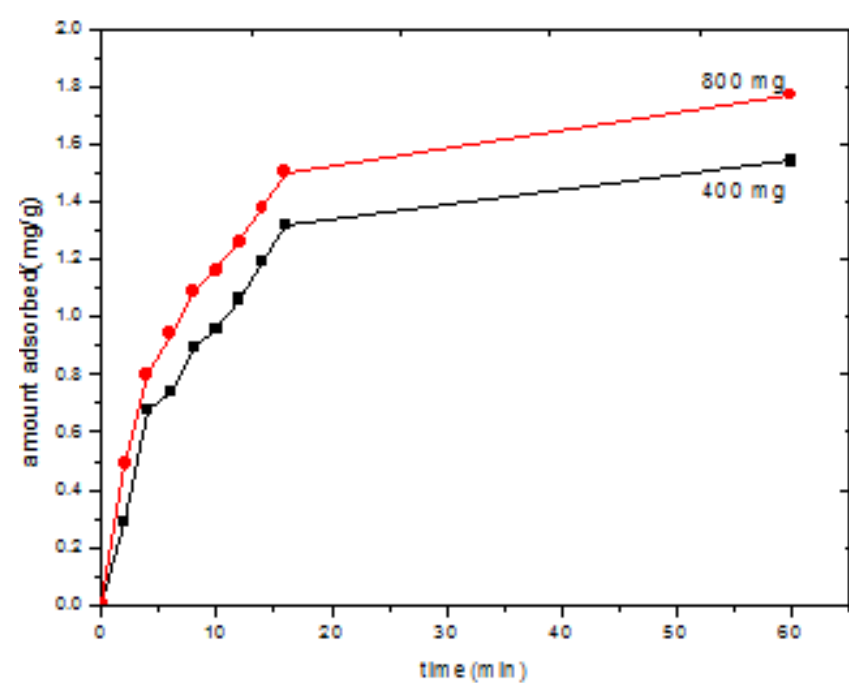

Figure 5: Effect of adsorbent dosages on removal of nickel. Condition: $\mathrm{pH}$ 5, initial concentration of metal solution $5 \mathrm{mg} / \mathrm{L}$, particle size $0.38-0.46 \mathrm{~mm}$ and room temperature

\section{Effect of particle size}

Nickel (II) solution was agitated with $400 \mathrm{mg}$ of RC in three different experiments (initial concentration: $5 \mathrm{mg} / \mathrm{L}$; particle sizes: 0.05-0.06 (BSS52), 0.38-0.46 (BSS30) and 0.65$0.91 \mathrm{~mm}$ (BSS25) $\mathrm{mm}$ at room temperature and $\mathrm{pH} 5$ ) in which the uptake was found to be 1.93, 1.54 and $1.37 \mathrm{mg} / \mathrm{g}$ respectively. Figure 6 shows that decrease of the particle size increases the adsorption of nickel(II) on RC. According to Weber and Morris the breaking of larger particle tends to open tiny cracks and channels on the particle surface, providing additional surface area which is useful in the adsorption process ${ }^{17}$. In general, the rate of removal of metal ion increases with the decrease in particle size of the adsorbent and the time required for $50 \%$ removal is also less while particles of smaller size is used. This relationship clearly demonstrates the advantage of powdered adsorbent materials over the granular particles from kinetic view point, indicating the external transport limits the rate of adsorption. The presence of larger number of smaller particles provides the sorption system a larger surface area available for nickel(II) removal and it also reduces the external mass transfer resistance.

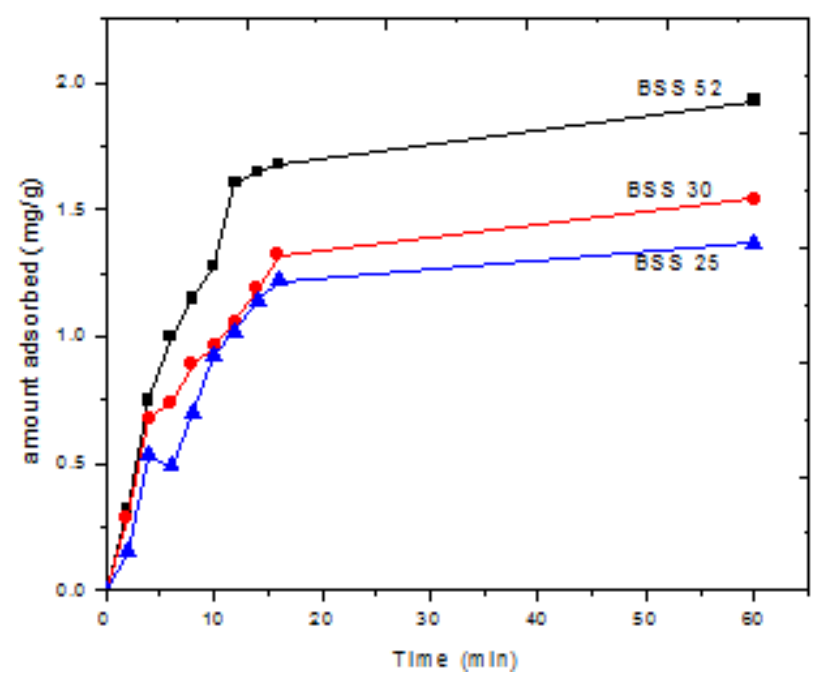

Figure 6: Effect of particle size on removal of nickel

Condition: initial metal ion concentration 5mg/L, $\mathrm{pH}$ 5, dosage $400 \mathrm{mg} / 200 \mathrm{ml}$ and room temperature.

\section{Activation Energy and Thermodynamic Parameters}

To determine the thermodynamic properties and thermal effects on the adsorption, the temperature variation experiments were conducted at 294, 301and 308K, with an initial nickel concentration $5 \mathrm{mg} / \mathrm{L}$ and $400 \mathrm{mg}$ of RC. The effect of temperature on adsorption is shown in Figure 7, which illustrates that the increase of the amount of the adsorbate is a function of temperature. This temperature dependence of adsorption process may be explained on the basis of thermodynamic parameters calculated using standard thermodynamic relationships. The thermodynamic parameters such as free energy, enthalpy and entropy changes can be estimated from the following equations ${ }^{18,19}$.

$$
\begin{aligned}
& \mathrm{K}_{\mathrm{c}}=\mathrm{C}_{\mathrm{i}} / \mathrm{C}_{\mathrm{e}} \\
& \Delta \mathrm{G}^{0}=-\mathrm{RT} \ln \mathrm{K}_{\mathrm{c}} \\
& \log \mathrm{K}_{\mathrm{c}}=\Delta \mathrm{S}^{0} / 2.303 \mathrm{R}-\Delta \mathrm{H}^{0} / 2.303 \mathrm{RT} \\
& \operatorname{lnK}=\ln \mathrm{A}-\mathrm{E}_{\mathrm{a}} / \mathrm{RT}
\end{aligned}
$$

where $C_{e}$ is the equilibrium concentration in solution in $\mathrm{mg} / \mathrm{L}$ and $\mathrm{C}_{\mathrm{i}}$ is the equilibrium concentration on the sorbent in $\mathrm{mg} / \mathrm{L}$ and $\mathrm{K}_{\mathrm{c}}$ is the equilibrium constant. The Gibbs free energy $\left(\Delta G^{0}\right)$ for the adsorption of nickel onto RC at all temperatures was obtained from equation 4 and are presented in Table 2. The values of $\Delta \mathrm{H}^{0}$ and $\Delta \mathrm{S}^{0}$ were calculated from the slope and intercept of the plot $\log \mathrm{K}_{\mathrm{c}}$ against $1 / \mathrm{T}$ (figure not given) and are also listed in table 2 . Where $\mathrm{K}$ is rate constant, Ea is activation energy and $\mathrm{A}$ is Arrhenius pre-exponential factors $(\mathrm{J} / \mathrm{mol})$ and activation energy was calculated by plotting $1 / \mathrm{T}$ versus $\operatorname{logK}$.

Table 2: Thermodynamic parameters for adsorption of

\begin{tabular}{|c|c|c|c|c|}
\multicolumn{5}{c|}{ nickel(II) onto raw cabbage } \\
\hline $\begin{array}{c}\text { Temp } \\
(\mathrm{K})\end{array}$ & $\begin{array}{c}\Delta \mathrm{G}^{0} \\
(\mathrm{~kJ} / \mathrm{mol})\end{array}$ & $\begin{array}{c}\Delta \mathrm{H}^{0} \\
(\mathrm{~kJ} / \mathrm{mol})\end{array}$ & $\begin{array}{c}\Delta \mathrm{S}^{0} \\
(\mathrm{~kJ} / \mathrm{mol})\end{array}$ & $\begin{array}{c}\mathrm{E}_{\mathrm{a}} \\
(\mathrm{kJ} / \mathrm{mol})\end{array}$ \\
\hline 294 & -1.112 & 50.02 & 0.1737 & -28.45 \\
301 & -2.399 & & & \\
308 & -3.456 & & & \\
\hline
\end{tabular}

From table 2 the value of $\mathrm{R}^{2}$ (0.999) obtained showed a good agreement between the entropy change and temperature. The negative values of $\Delta \mathrm{G}^{0}$ measured at 294, 301, and $308 \mathrm{~K}$ indicate spontaneous nature of adsorption process for nickel(II) ion. The value of $\Delta \mathrm{G}^{0}$ confirms the maximum adsorption at higher temperatures, because there is a gradual decrease in $\Delta \mathrm{G}^{0}$ value with rise in temperature. The positive value of enthalpy change, $\Delta \mathrm{H}^{0}$, shows the adsorption is endothermic and the positive value of $\Delta \mathrm{S}^{0}$. A highly disordered process was also indicated by the positive value of $\Delta \mathrm{S}^{0}$. Similarly, the positive enthalpy change showed an endothermic adsorption process, which implies an increase in adsorption capacity with temperature increase. The $E_{a}$ value calculated from the slope of the plot was found to be $28.45 \mathrm{~kJ} / \mathrm{mol}$. (lesser Ea value faster the reaction) The negative value of $E_{a}$ indicates that lower solution temperatures favours metal ion removal by adsorption onto $\mathrm{RC}$ surface and the adsorption process is endothermic in nature. 


\section{International Journal of Science and Research (IJSR) \\ ISSN (Online): 2319-7064}

Index Copernicus Value (2013): 6.14 | Impact Factor (2015): 6.391.1

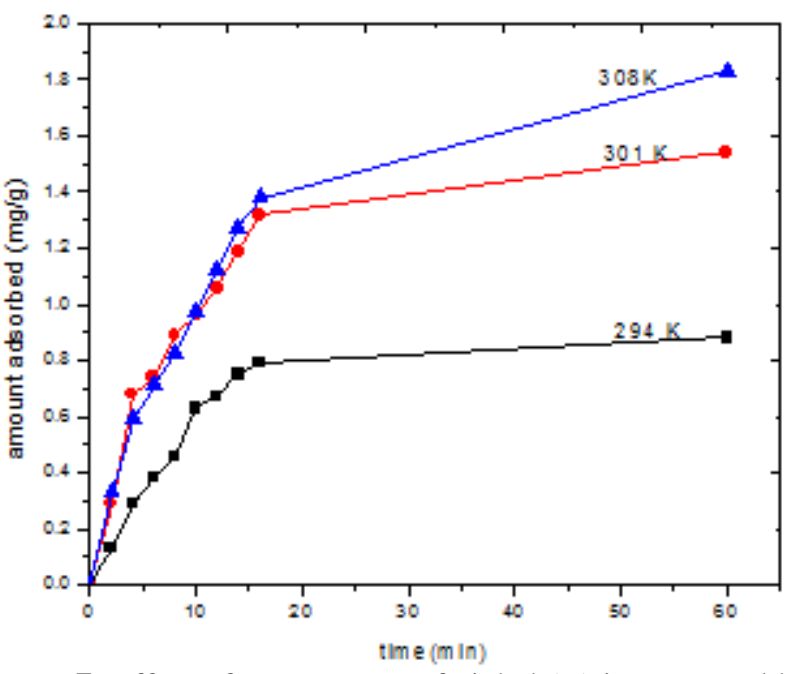

Figure 7: Effect of temperature of nickel (II) ion removal by RC. Conditions: pH 5, initial concentration $5 \mathrm{mg} / \mathrm{L}$, dosage $400 \mathrm{mg} / 200 \mathrm{~mL}$ and particle size $0.38-0.46 \mathrm{~mm}$

\section{Adsorption Isotherms}

An adsorption isotherm represents the equilibrium relationship between the adsorbate concentration in the liquid phase and that on the adsorbents surface at a given condition. A number of isotherms have been developed to describe equilibrium relationships. In the present study Freundlich, Langmuir and Temkin models were used to describe the equilibrium data. The results are shown in Table 3 (and the modeled isotherm are plotted in figure 8,9 and 10).

\section{The Langmuir Isotherm}

The Langmuir Isotherm model ${ }^{20}$ was used to describe observed sorption phenomena and suggests that uptake occurs on a homogeneous surface by monolayer sorption without interaction between adsorbed molecules. The linear forms of the equation can be written as:

$$
\mathrm{C}_{\mathrm{e}} / \mathrm{q}_{\mathrm{e}}=1 / \mathrm{Q}_{0} \mathrm{~b}+\mathrm{C}_{\mathrm{e}} / \mathrm{Q}_{\mathrm{o}}
$$

Where $\mathrm{q}_{\mathrm{e}}$ is the amount adsorbed $(\mathrm{mg} / \mathrm{g}), \mathrm{C}_{\mathrm{e}}$ is the equilibrium concentration of the metal ions $(\mathrm{mg} / \mathrm{L}), \mathrm{Q}_{0}$ $(\mathrm{mg} / \mathrm{g})$ is the maximum amount of adsorbed metal ion per unit mass of sorbent corresponding to complete coverage of the adsorptive site, ,be $(\mathrm{L} / \mathrm{mg})$ is the Langmuir constant related to the energy of adsorption. The Langmuir Isotherm model was chosen for the estimation of maximum adsorption capacity corresponding to complete monoloayer coverage on the RC surface. The plots of specific sorption $\left(\mathrm{C}_{\mathrm{e}} / \mathrm{q}_{\mathrm{e}}\right)$ against the equilibrium concentration $\left(\mathrm{C}_{\mathrm{e}}\right)$ for nickel(II) are shown in Fig.8 and the linear isotherm parameters, $Q_{0}, b$ and the coefficient of determinations are presented in Table 3. It was observed that the Langmuir adsorption Isotherm is satisfactory describes the sorption of nickel(II) from aqueous solution using RC as indicated by the high correlation coefficient $\left(\mathrm{r}^{2}\right)$ of 0.9875 . The applicability of the Langmuir Isotherm indicates good monolayer coverage of nickel(II) ions on the RC which consequently suggests the formation of a monolayer on the adsorbent surface in the given concentration range ${ }^{21}$. The fact that the Langmuir Isotherm fits the experimental data very well may be due to the homogeneous distribution of active sites on the adsorbent since the Langmuir equation assumes that the surface is homogenous. The shape of the
Langmuir Isotherm can be used to predict whether a sorption system is favourable or unfavourable in a batch adsorption process. The essential features of the isotherm can be expressed in terms of a dimensionless constant separation factor $\left(\mathrm{R}_{\mathrm{L}}\right)$ that can be defined by the following relationship ${ }^{22}$.

$\mathrm{R}_{\mathrm{L}}=1 / 1+b \mathrm{C}_{\mathrm{o}}$ The values of $\mathrm{R}_{\mathrm{L}}$ indicated the type of Langmuir isotherm to be irreversible $\left(\mathrm{R}_{\mathrm{L}}=0\right)$, favourble $\left(0<R_{L}<1\right)$, linear $\left(R_{L}=1\right)$, or unfavourable $\left(R_{L}>1\right)$. The values of $R_{L}$ obtained in this study were found to lie between 0 and 1 , indicating favourable adsorption.

\section{The Freundlich Isotherm}

The Freundlich Isotherm is applicable to non-ideal adsorption on heterogeneous surfaces and the linear form of the isotherm can be represented $\mathrm{as}^{23}$.

$$
\log \mathrm{q}_{\mathrm{e}}=\log \mathrm{K}_{\mathrm{F}}+1 / \mathrm{n} \log \mathrm{C}_{\mathrm{e}}
$$

Where $K_{F}$ is the Freundlich constant related to sorption capacity $\left(\mathrm{mgg}^{-1} \mathrm{Lg}^{1 / \mathrm{n}}\right)$ and , $\mathrm{n}^{\mathrm{ec}}$ is related to the adsorption intensity of the adsorbent ${ }^{24}$. Where $K_{F}$ and $n$ can be determined from the linear plot of $\log q_{e} v s \log C_{e}$. The evaluated constants are given in Table 3 .

Table 3: Isotherm model constants and correlation coefficients for $\mathrm{Ni}(\mathrm{II})$ ions from adsorption from aqueous solution using RC

\begin{tabular}{|c|c|c|}
\hline Langmuir Isotherm & Freundlich Isotherm & Temkin Isotherm \\
\hline $\mathrm{Q}_{0}=0.6292$ & $\mathrm{~K}_{\mathrm{F}}=2.396$ & $\mathrm{~B}_{\mathrm{T}}=2.109$ \\
$\mathrm{~b}=1.04$ & $\mathrm{n}=1.206$ & $\mathrm{~K}_{\mathrm{T}}=0.970$ \\
$\mathrm{R}_{\mathrm{L}}=2.89$ & $\mathrm{r}^{2}=0.9717$ & $\mathrm{r}^{2}=0.976$ \\
$\mathrm{r}^{2}=0.9875$ & & \\
\hline
\end{tabular}

The Freundlich exponent, " $n$ "e should have values lying in the range of 1 to 10 for classification as favourable adsorption ${ }^{25}$. The Freundlich model was chosen to estimate the adsorption intensity of the sorbate on the sorbent surface. The experimental data from the batch sorption study of the metal ions on RC was plotted logarithmically in Figure 9. The linear Freundlich isotherm constants for $\mathrm{Ni}(\mathrm{II})$ on RC is presented in Table 3. The Freundlich isotherm parameter , $n^{\text {ce }}$ measures the adsorption intensity of metal ions on the RC. The high , $\mathrm{n}^{\text {ee }}$ value of $\mathrm{Ni}$ (II) ion indicate the preferential sorption of metal ion probably due to its smaller ionic radius and shows the ability of the RC to remove the metal ions from solution even at high concentration. The ultimate adsorption capacity $\mathrm{K}_{\mathrm{F}}$ of the adsorbent was calculated from the isothermal linear regression equation. The $K_{F}$ value 2.396( $\mathrm{mgg}^{-1} \mathrm{Lg}^{1 / \mathrm{n}}$ ) suggesting and conforming that $\mathrm{Ni}(\mathrm{II})$ has greater adsorption tendency towards the RC. Similar results are reported ${ }^{26}$.

\section{Temkin Isotherm}

The Temkin isotherm equation assumes that the heat of adsorption of all the molecules in layer decreases linearly with coverage due to adsorbent-adsorbate interactions and that the adsorption in characterized by a uniform distribution of the bonding energies up to some maximum binding energy.

The Temkin isotherm is represented as 


\section{International Journal of Science and Research (IJSR) \\ ISSN (Online): 2319-7064}

Index Copernicus Value (2013): 6.14 | Impact Factor (2015): 6.391.1

$\mathrm{q}_{\mathrm{e}}=\mathrm{B}_{\mathrm{T}} \ln \mathrm{K}_{\mathrm{T}}+\mathrm{B}_{\mathrm{T}} \ln \mathrm{C}_{\mathrm{e}}$

$\mathrm{qe}=\mathrm{RT} / \mathrm{b}_{\mathrm{T}} \ln \mathrm{K}_{\mathrm{T}}+\mathrm{RT} / \mathrm{b}_{\mathrm{T}} \ln \mathrm{C}_{\mathrm{e}}$

where $\mathrm{T}$ is the absolute temperature $(\mathrm{K}), \mathrm{R}$ is the gas constant(8.314 J/kmol), $\mathrm{K}_{\mathrm{T}}$ is the equilibrium binding constant $(\mathrm{L} / \mathrm{mg}), \quad \mathrm{b}_{\mathrm{T}}$ is the variation of adsorption energy $(\mathrm{kJ} / \mathrm{mol})$ and $\mathrm{B}_{\mathrm{T}}$ is Temkin constant related to the best of adsorption $(\mathrm{kJ} / \mathrm{mol})$. The Temkin adsorption isotherm model was chosen to evaluate the adsorption potentials of the adsorbent for the adsorbates ${ }^{27}$. The Temkin isotherm plot for the nickel(II) ions is presented in Figure $\mathbf{1 0}$ and the parameters is given in Table 3 . The Temkin adsorption potential, $\mathrm{K}_{\mathrm{T}}$ of $\mathrm{RC}$ of $\mathrm{Ni}(\mathrm{II})$ is $0.970(\mathrm{~L} / \mathrm{mg})$, the Temkin constant, $\mathrm{b}_{\mathrm{T}}$ related to heat of sorption for the metal ion is $2.108 \mathrm{~kJ} / \mathrm{mol}$

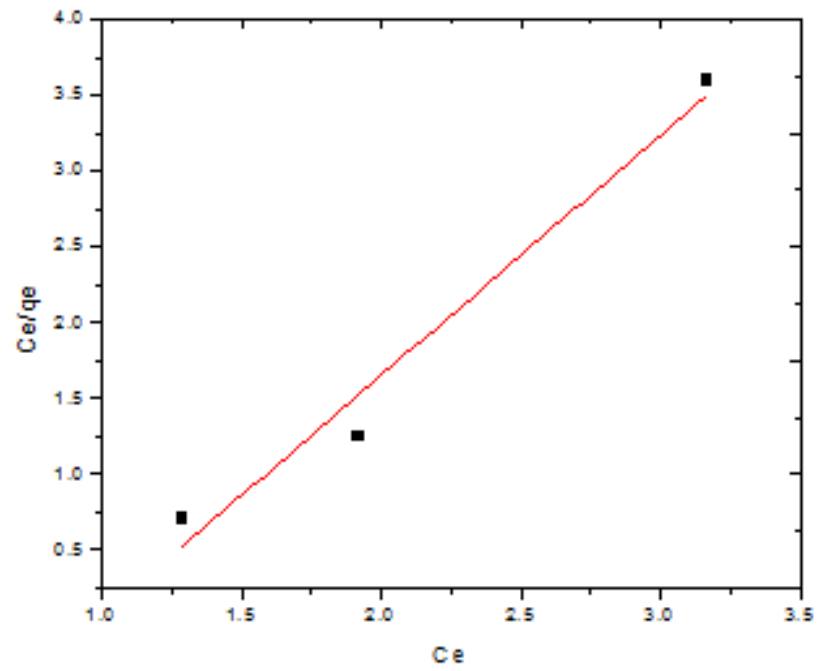

Figure 8: Langmuir adsorption isotherm for adsorption of nickel(II) ions on RC

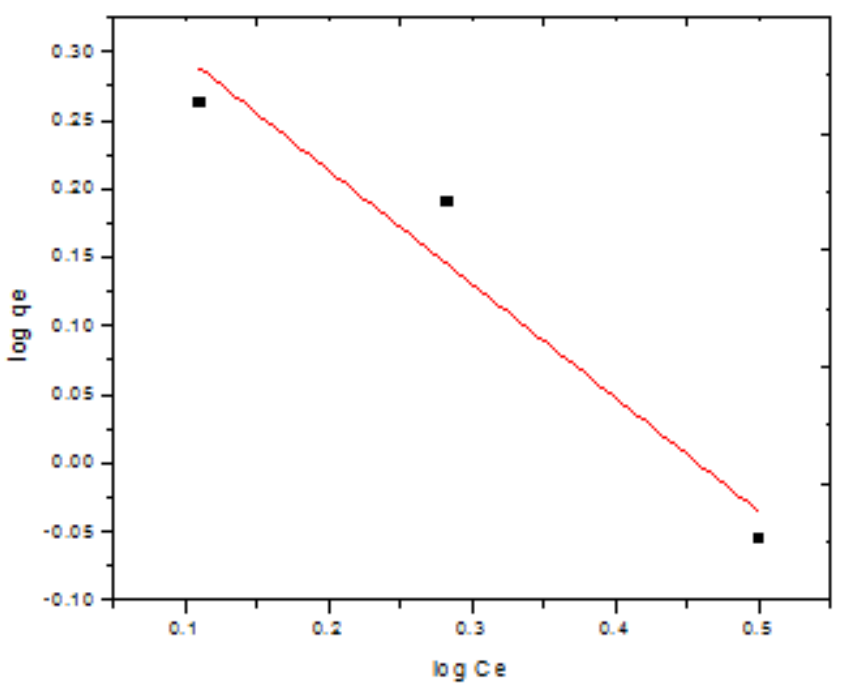

Figure 9: Freundlich adsorption isotherm for adsorption of nicke(II) ion on RC

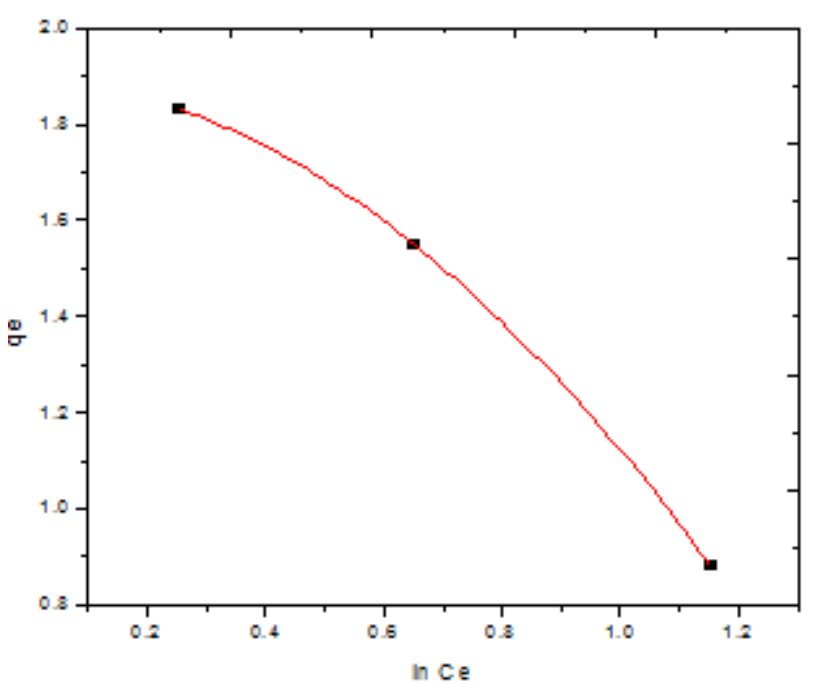

Figure 10: Temkin adsorption isotherm for adsorption of nickel(II) ions on RC

\section{Batch Kinetic Studies}

Kinetic studies are significant for any kind of biosorption processes. Adsorption kinetics not only describes the adsorption mechanism of metals on adsorbents but also describe the metal adsorption rate which controls the contact time of metals at the solid-liquid interface ${ }^{28}$. Various kinetic models have been used by various researchers whereas in this study the pseudo-first, pseudo-second order models and intraparticle diffusion were studied. Batch kinetic experiments were conducted for nickel(II) ion solutions at pH 5 with $400 \mathrm{mg} / 200 \mathrm{~mL}$ of adsorbent (particle size 0.38 $0.46 \mathrm{~mm}$ ) at three temperatures. Kinetics of sorption describing the solute uptake rate, which in turn governs the residence time of sorption reaction, is one of the important characteristics defining the efficiency of sorption. The rate constant of adsorption of the metal ion on adsorbents is described by Lagergren ${ }^{29}$ equation(11) or pseudo-first order and pseudo-second order equation(12)

$$
\begin{aligned}
& \log \left(\mathrm{q}_{\mathrm{e}}-\mathrm{q}\right)=\log \mathrm{q}_{\mathrm{e}}-\mathrm{k}_{\mathrm{ad}} \mathrm{t} / 2.303 \\
& \mathrm{t} / \mathrm{q}_{\mathrm{t}}=1 / \mathrm{k}_{2} \mathrm{q}_{\mathrm{e}}{ }^{2}+\mathrm{t} / \mathrm{q}_{\mathrm{e}}
\end{aligned}
$$

where $\mathrm{q}_{\mathrm{e}}$ is the amount of solute adsorbed at equilibrium per unit weight of adsorbent $(\mathrm{mg} / \mathrm{g})$, , $\mathrm{q}^{\text {ee }}$ the amount of solute adsorbed at any time, ,te $(\mathrm{mg} / \mathrm{g})$ and, $\mathrm{k}_{\mathrm{ad}}{ }^{\text {ee }}$ the adsorption constant and $\mathrm{k}_{2}$ is the pseudo-second order rate constant. Linear plots of $\log \left(\mathrm{q}_{\mathrm{e}}-\mathrm{q}\right)$ versus $\mathrm{t}$ suggest the applicability of the first order kinetics. The rate constants, $\mathrm{k}_{\mathrm{ad}}$, were calculated from the slope of the figure 11. By regression modelling, experimental curves were found to be the best fit for the data characterized by the regression coefficient $\left(\mathrm{r}^{2}\right)$. Adsorption on solid phase leads to the establishment of equilibrium between two phases, the equilibrium constant $\mathrm{K}_{\mathrm{c}}$ was calculated equation (3).

In figure 12 pseudo second order kinetic model of $t / q_{t}$ versus „te. The contact time experimental results can be used to study the rate-limiting step in the adsorption process. One might then postulate that the rate-limiting step may be either film or intraparticle diffusion. The rate constant for intraparticle diffusion $\mathrm{k}_{\mathrm{id}}\left(\mathrm{mg} / \mathrm{g} / \mathrm{min}^{1 / 2}\right)$ is given by equation (13) 


\section{International Journal of Science and Research (IJSR) \\ ISSN (Online): 2319-7064}

Index Copernicus Value (2013): 6.14 | Impact Factor (2015): 6.391.1

$$
\mathrm{q}=\mathrm{k}_{\mathrm{id}} \mathrm{t}^{1 / 2}
$$

where $\mathrm{q}$ is the amount adsorbed $(\mathrm{mg} / \mathrm{g})$ at time , $\mathrm{tc}^{\mathrm{ec}}(\mathrm{min}$.$) . \mathrm{k}_{\mathrm{id}}$ values were obtained from the slope of linear plot of , $\mathrm{q}^{\text {ce }}$ versus $t^{1 / 2}$. The rate constant, $k_{a d}, k_{2}$, equilibrium constant, $\mathrm{K}_{\mathrm{c}}$ calculated $\mathrm{q}_{\mathrm{e}}$, regression coefficient $\left(\mathrm{r}^{2}\right)$ and intraparticle constant, $\mathrm{k}_{\mathrm{id}}$ for all systems were calculated and given in table 4. As shown in this table, the correlation coefficients $\left(\mathrm{r}^{2}\right)$ for the first order rate equation are greater than 0.98 and substantially higher than that for the second order rate equation. This show that the adsorption of $\mathrm{Ni}(\mathrm{II})$ ion on RC can be represented by the pseudo first-order model. Figure 13 presents intraparticle plot for Ni(II) onto RC. The calculated diffusion coefficient $\mathrm{k}_{\mathrm{id}}$ values are listed in table 4 . The $\mathrm{k}_{\mathrm{id}}$ value was higher at the higher concentrations. Intraparticle diffusion is the sole ratelimiting step if the regression of , $\mathrm{q}^{\text {ee }}$ versus $\mathrm{t}^{1 / 2}$ is linear and did not passing through the origin. This deviation from the origin is due to the difference in the rate of mass transfer in the initial and final stages of the sorption. This indicated the existence of some boundary layer effect and further showed that intraparticle diffusion was not the only rate limiting step $^{30}$.

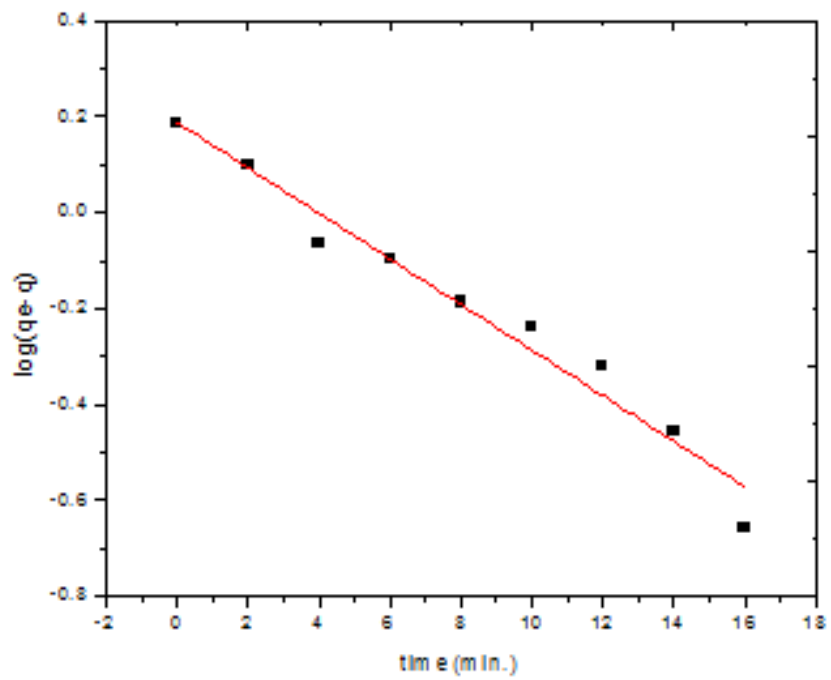

Figure 11: Pseudo-first order kinetic plots for adsorption of Ni(II) onto RC. Conditions: pH 5, dose 400mg/200mL, particle size $0.38-0.46 \mathrm{~mm}$, initial metal ion concentration $5 \mathrm{mg} / \mathrm{L}$ and temperature $301 \mathrm{~K}$

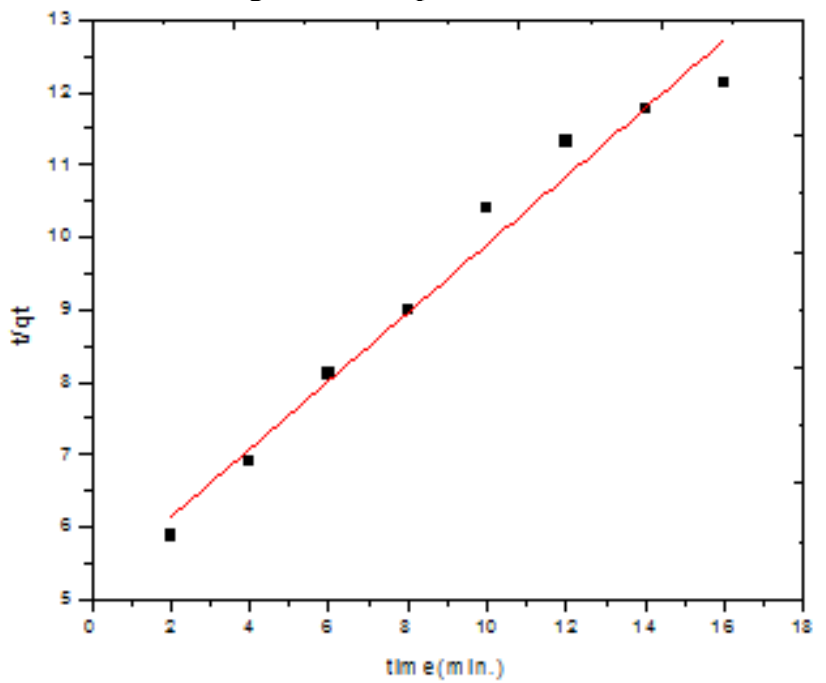

Figure 12: Pseudo-second order kinetic plots for adsorption of $\mathrm{Ni}(\mathrm{II})$ onto RC. Conditions: $\mathrm{pH} 5$, dose $400 \mathrm{mg} / 200 \mathrm{~mL}$, particle size $0.38-0.46 \mathrm{~mm}$, initial metal ion concentration $5 \mathrm{mg} / \mathrm{L}$ and temperature $301 \mathrm{~K}$

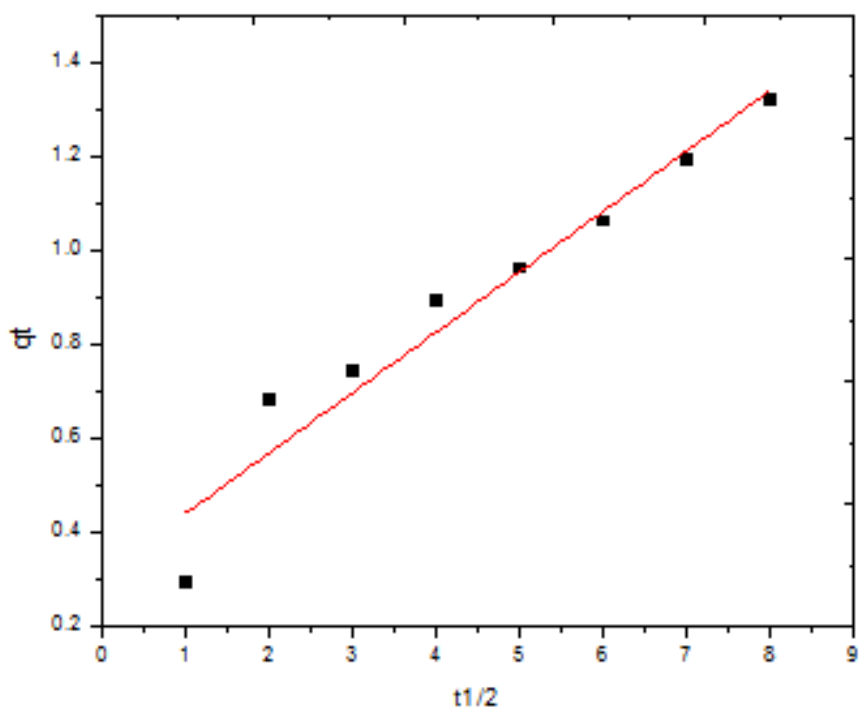

Figure 13: Intraparticle diffusion model for adsorption of Ni(II) onto RC. Conditions: pH 5, dose 400mg/200mL, particle size $0.38-0.46 \mathrm{~mm}$, initial metal ion concentration $5 \mathrm{mg} / \mathrm{L}$ and temperature $301 \mathrm{~K}$

Table 4: Parameters of the kinetic models for the adsorption of $\mathrm{Ni}(\mathrm{II})$ onto RC.

\begin{tabular}{|c|c|c|c|}
\hline Model & $294 \mathrm{~K}$ & $301 \mathrm{~K}$ & $308 \mathrm{~K}$ \\
\hline Pseudo-first order & & & \\
$\mathrm{k}_{\mathrm{ad}}$ & 0.1428 & 0.1082 & 0.0826 \\
$\mathrm{r}^{2}$ & 0.9854 & 0.9834 & 0.9933 \\
\hline Pseudo-second order & & & \\
$\mathrm{k}_{2}$ & 0.1538 & 0.1223 & 0.084 \\
$\mathrm{q}_{\mathrm{e}}$ & 1.2090 & 1.5730 & 1.690 \\
$\mathrm{r}^{2}$ & 0.7610 & 0.9089 & 0.889 \\
\hline Intraparticle diffusion & & & \\
$\mathrm{k}_{\mathrm{id}}$ & 0.1005 & 0.1470 & 0.1610 \\
$\mathrm{r}^{2}$ & 0.9874 & 0.9634 & 0.9850 \\
\hline
\end{tabular}

\section{Desorption}

Desorption studies were carried out as follows: In an adsorption experiment, the residual metal ion solution was filtered to separate the adsorbent and gently washed with distilled water to remove any unadsorbed chromium ion. Solid containing the metal ions was dried at $60^{\circ} \mathrm{C}$ and stored in a container, about, $1 \mathrm{~g}$ of sample was suspended in $50 \mathrm{~mL}$ of distilled water. Desorption rate was slow and the amount released was also very less. This indicated that the major portion of Nickel(II) ion was, probably, bound to the sorbent through stronger interactions. The percentage of removal of metal ion from the adsorbent is approximately $15 \%$.

\section{Conclusion}

This study investigated the feasibility of raw cabbage used as a low cost adsorbent for the removal of Nickel(II) ion from aqueous solution. The adsorption process is also dependent on numerous factors such as the solution $\mathrm{pH}$, contact time, initial concentration, adsorbent dosage, adsorbent particle size and temperature. The amount of adsorption of nickel ions increased with an increase in the 


\section{International Journal of Science and Research (IJSR) \\ ISSN (Online): 2319-7064}

Index Copernicus Value (2013): 6.14 | Impact Factor (2015): 6.391.1

nickel concentration, it increased with increase in contact time and adsorbent dose upto a certain level. The maximum removal was found at $\mathrm{pH}$ 5.0. Equilibrium data fitted very well in the Langmuir isotherm equation, confirming the monolayer adsorption capacity of $\mathrm{Ni}$ (II) ions onto raw cabbage. The adsorption kinetics followed pseudo-first order kinetic model with a good correlation, intraparticle diffusion was not the sole rate controlling factor. The activation energy of the adsorption process(Ea) was found to be $-28.45 \mathrm{~kJ} / \mathrm{mol}^{-1}$ by using the Arrhenius equation, indicating exothermic nature of nickel adsorption onto RC. Thermodynamic analysis suggests that the removal of nickel from aqueous solution by raw cabbage was a spontaneous, exothermic and randomness. Therefore, the present findings suggest that raw cabbage may be used as an inexpensive and effective adsorbent without any treatment or any other modification for the removal of nickel ions from wastewater.

\section{References}

[1] Iqbal, $M$ et al., Minerals Engineering, 17, 217-223, 2004.

[2] Ko, D.C.K, Porter, J.F. and Mckay.G, Chem. Eng. Sci., 55,5819-5829, 2000.

[3] Huang, C.P and Wu, M.H, J. Water. Pollut. Control Fed., 47, 2437-2445, 1975.

[4] Wase J, Forster C, Biosorbents for Metal ions. Taylor and Francis Ltd., 1997.

[5] Dhara. S.S. A textbook of environmental chemistry and pollution control, $3^{\text {rd }}$ edition. S.Chand and company Ltd, New Delhi, 2000.

[6] Pani Balram, A text book of environmental Chemistry, J.K. International publications, New Delhi, 2007.

[7] Giles, H, Nakhwa, S.N. J.Appl.Chem., 12, 1962.

[8] Mallikarjuna, N.N., Venkataraman. A, Talanta, 60, 139147, 2003.

[9] Flaviane et al J. Hazard. Mater., 176, 856-863, 2010.

[10] H. Niu, X. Shu,J.H. Wang and B. Volesky, "Removal of lead from aqueous solution by penicillium biomass,", Biotechnol. Bioeng. Vol.42pp 785-789, 1993.

[11] Achak. M, Hafidi A, Quazzani. N, Sayadic S and Mandi L. " Low cost biosorbent banana peel for the removal of phenolic compounds from olive mill wastewater. Kinetic and equilibrium studies, J.Hazard. Mate., vol.166, pp. 117-125, 2009.

[12] S.A.Ghanem and D.S. Mikklelsen, "Sorption of zinc on iron hydrous oxide, "Soil.Sci, Vol.146, pp. 15-21, 1988.

[13] M.E. Argun, S. Dursun, C.Ozdemir, and M.Karatas," Heavy metal adsorption by modified oak sawdust: thermodynamics and kinetics", J.Hazard.Mater., Vol.141, pp.77-85, 2007.

[14] R. Vimalar and N. Das, "Biosorption of cadmium and lead from aqueous solution using mushrooms: a comparative study," J.Hazard.Mater. Vol.168, pp.376382, 2009.

[15] Gupta. R, and Mohapatra H., Microbial biomass: An economical alternative for removal of heavy metals from waste water, Indian Journal of Exp. Biol. 41, 945966, 2003.

[16] Karthikeyan S, Balasubramanian R and Iyer CSP, "Evaluation of the marine algae Ulva fasciata and sargassum sp. For the biosorption of $\mathrm{Cu}(\mathrm{II})$ from aqueous solutions". Biores. Tech.,Vol.98, pp. 452-455, 2007.

[17] W.J. Weber and J.C. Morris, J. San.Engg.Div. ASCE, 89(SA2), 31-39, 1963.

[18] Anirudhan, T.S and Radhakrishnan, P.G Thermodynamics and kinetics of adsorption of $\mathrm{Cu}(\mathrm{II})$ from aqueous solutions onto a new cation exchanger derived from tamarind fruit shell. J. Chem. Thermodynamics, 40(4), 702-709, 2008.

[19] Anwar J, Shafique U, Zaman W, Salman M, Dar A and Anwar S, Removal of $\mathrm{Pb}(\mathrm{II})$ and $\mathrm{Cd}(\mathrm{II})$ from water by adsorption on peels of banana, Biores.,Tech., vol.101, pp.175-1755, 2010.

[20] Langmuir. I, J.Am.Chem.Soc., 40, 1918.

[21] Sujana, M.G, Pradhan, H.K and Anand. S, "Studies on sorption of some geomaterials for fluoride removal from aqueous solutions. J. Hazard. Mater., 161(1), 120-125, 2009.

[22]H. Ali and S.K. Mohammed, Biosorption of crystal violet from water on leaf biomass of calotropis procera, Journal of Environmental science and Technology, 1(3), 143-150, 2008.

[23] Freundlich. H.M.F., Over the adsorption in solution. J. Phys. Chem., 57, 385-471, 1906.

[24] Chantawong, V. Harvey, N.W., and Bashlain V.N., Comparison of heavy metal adsorptions by Thai Kaolin and ball clay, Water Air Soil Pollution, 148, 111-125, 2003.

[25]Bansal, R.C., and Goyal.M, Activated Carbon adsorption, Boca Ratron, Crc Press Tayor Francis Group, 2005.

[26] Aoyama, M. Removal of $\mathrm{Cr}(\mathrm{VI})$ from aqueous solution by London plane leavese. Journal of Chemical Technology and Biotechnology, vol.78, pp601-604, 2003.

[27] Ho, Y.S., Wase, D.A.J. and Forster, C.F. Removal of lead ions from aqueous solution using sphagnum moss peat a adsorbent. Water SA, 22(3), 219-224, 1996.

[28] Ho YS, Mckay. G, The sorption of lead(II) ions on peat. Water Res., 33; 578-584, 1999.

[29] Langergen, S. About the theory of so-called adsorption of soluble substances, Kungliga svenska veensk Handl., 24, 1-39, 1898.

[30] Sari, A. Citak, /d. and Tuzen, M. Equilibrium, themodynamic and kinetic studies on adsorption of $\mathrm{Sb}$ (II) from aqueous solution using low cost natural diatomite. Chem. Eng.J., 162(2), 521-527, 2010. 